\title{
Factors influencing energy efficiency in the German and Colombian manufacturing industries
}

\author{
Clara Inés Pardo Martínez \\ University of Wuppertal, Wuppertal Institute and University of La Salle \\ Germany and Colombia
}

\section{Introduction}

Energy is a basic factor for industrial production, and the level of electricity consumption is used to measure the progress and economic development of nations. Globally, growing population, industrialisation and rising living standards have substantially increased dependence on energy. As a result, the development of conventional energy resources, the search for new or renewable energy sources, energy conservation (using less energy), and energy efficiency (same service or output, less energy) have become unavoidable topics within politics.

Generally, an ideal policy cycle sees a given policy formulated, implemented, monitored and evaluated to verify its effectiveness and fulfilment of the proposed objectives and in accordance with the results of this evaluation, the policy is then kept, reformulated or abolished. In this cycle-and above all, in industrial energy politics-it is important that the policy makers recognise the influence of economic, technical and political factors and have an understanding of the mechanisms that determine energy efficiency performance such that the instruments and strategy they formulate become successful.

Strategies and instruments developers drafting an energy policy need to understand the behaviour of the manufacturing industry with respect to energy consumption in order to (i) motivate, (ii) target energy actions that will be adopted, and (iii) develop energy saving and energy efficiency actions and technologies that will be of interest (Kant, 1995 and Thollander et al., 2007). The quantity and quality of energy conservation support or energy efficiency programs will depend on perceived interest and as well as the need for energy conservation changes.

There are limited studies and information currently available on the perception of approach to energy efficiency in companies. Therefore, this study seeks to analyse the factors and strategies that address energy efficiency in the manufacturing industries. This information may be useful for energy policy and program development as well as pollution prevention and energy efficiency strategies. The research questions that guide this chapter are:

- What is the role of energy consumption and energy efficiency in business strategies in the manufacturing industries?

- What are the variables of political factors that may have more influence on energy efficiency performance? 
- What are the strategies and instruments that may generate better results to improve energy efficiency in the manufacturing industries?

These questions were investigated in this study by means of the opinions and expectations of the main stakeholders (associations and representative firms in Germany and Colombia) through a questionnaire and analysis of literature.

This chapter is structured as follows. In section 2, examines energy efficiency policy in both countries. Section 3 shows the methodology used in this study. Section 4 analyses changes in energy efficiency in German and Colombian manufacturing industries. Results and discussion appear in section 5 while the section 6 shows different strategies and recommendations for an effective energy efficiency policy in the Colombian manufacturing industry. The main conclusions of the study are presented in section 7 .

\section{General characteristics of energy efficiency policy in Germany and Colombia}

\subsection{The German energy efficiency policy}

The German energy policy is based in the commitment to the " 3 Es": energy security, economic efficiency and environmental sustainability. In this context, Germany emphasises environment and climate change objectives, and energy efficiency assumes increased importance in the country's overall energy policy. Moreover, in the last decade, the key German energy policies have been based on the expansion of the use of renewable energy and the establishment of new energy efficiency targets and an energy research program (IEA, 2007).

From the mid-1990s, the dominant instruments employed to improve energy efficiency in the German manufacturing industries were voluntary agreements. Since its introduction in 2004, however, the emissions trading system has become the most important policy measure in the manufacturing industrial sector, and it has also provided a key incentive to raise energy efficiency (Eichhammer, et al., 2006).

Regarding cross-cutting measures to improve energy efficiency in Germany, the main policy is the Ecological Tax Reform, i.e., the introduction of a so-called Eco Tax on oil, gas and electricity 1 . Additionally, the Renewable Energy Sources Act provides digressive compensation rates for new installations for all renewable energies ${ }^{2}$.

The German energy efficiency policies for the manufacturing industries have worked mainly with the following strategies:

- Voluntary agreements: the improvements in the efficiency of on-site electricity generation, particularly combined heat and power (CHP).

- $\quad$ Eco-tax: Germany's red-green coalition government introduced a set of ecotaxes on 1 April 1999 designed to make energy and resource consumption more expensive while lowering the cost of labour. Taxes on petrol and diesel, electricity, heating oil and natural gas had

1 The tax was introduced in two stages: a first tax increase from 1 April 1999 and a further four-step increase in taxation from 2000 to 2003. There are tax reductions for some consumers, chiefly within the manufacturing industry, agriculture and the railways. The revenue from this tax is used for a reduction of the non-wage labour costs and the promotion of renewable energies (Eichhammer, et al. 2006).

2 The rates are adapted to the efficiency potential of the different branches. This will provide a strong incentive to reduce costs and increase efficiency (Eichhammer, et al. 2006). 
been increased in five stages, and the bulk of the tax revenue generated used to reduce pension insurance contributions.

- Emission trading system means to achieve ecological and economic success. It means assuring the ecological integrity of the instrument, competition neutrality and low transaction costs. In other words, the emission trading system makes use of market-based mechanisms to encourage the reduction of greenhouse gas emissions in a cost-effective and economically-efficient manner, while maintaining the environmental integrity of the system.

- $\quad$ Specific Regulations such as: the Energy Performance of Buildings that seek to promote the energy performance of buildings taking into account outdoor climatic and local conditions as well as indoor climate requirements and cost-effectiveness, and the Minimum Energy Performance Standards for appliances or equipments and mandatory labels that are used to increase the energy efficiency of individual technologies.

- $\quad$ German CHP Law supports of cost efficient technology to reduce $\mathrm{CO}_{2}$ emissions. This law contains the definition of CHP electricity and heat; support mechanism for high efficiency $\mathrm{CHP}$, and mechanise to supervise reporting of $\mathrm{CHP}$ electricity production in $\mathrm{CHP}$ plants.

- $\quad$ Renewable Energy Sources Act creates a feed-in tariff system which requires utilities to purchase a predetermined amount of renewable energy at a fixed price. The policy provides economic security for investors and manufacturers and is responsible for the bulk of Germany's dynamic scale-up of renewable electricity capacity and equipment production.

- Grants and loans: the Kreditanstalt für Wiederaufbau (KfW) Umweltprogramm (Environment Program) that provides capital for investment in environmental protection activities and the low-interest loans to SMEs that can be used to supplement the European Recovery Programme's Environment and Energy Saving Program.

- $\quad$ Technology specific rebates are programs used to promote energy management and new energy-efficient technologies.

- $\quad$ Public information and advice: the sub-project under the Initiative Energieeffizienz (Energy Efficiency Initiative) campaign, DENA, the German Energy Agency.

\subsection{The Colombian energy efficiency policy}

In 1991, with the introduction of the new Constitution, Colombia adopted the principles of sustainable development as a guide to economic development and assigned to municipalities the duty to regulate especially the industry and energy intensive activities. The deregulation of the Colombian electricity system ${ }^{3}$ began in the same period, as did the restructuration of the public environmental management system ${ }^{4}$. These elements have characterised the development of energy policies in this country, where the emphasis has

3The Colombian electricity industry is characterized by a large hydroelectricity component, close to $70 \%$, and is considered to be one of the most open markets in the developing world, and the market evolution with this model has been satisfactory in terms of investment, competition, efficiency and reduction in electricity losses (Larsen et al., 2004).

4The Colombian environmental administration characterizes to be decentralized, democratic, participatory, fiscally solvent, and socially legitimate with measures as a system of pollution taxes, require environmental impact assessments for large construction projects, and institutionalize legal remedies against polluters (Blackman et al., 2006). 
been on the formulation of projects and regulations concerning energy efficiency in the manufacturing industrial sector. Moreover, additional instruments for environmental management involve agreements with industry or other relevant organisations. In 1997, the National Environmental Council approved the National Policy of Clean Production. The key objectives of this consensus-based energy policy were to increase the environmental efficiency and quality of energy resources and to develop environmental guides (guias ambientales) detailing options for improving energy efficiency performance in specific sectors. Other strategies used to increase energy efficiency in the manufacturing industries included the establishment of the energy excellence program (Merito URE), the conversion of urban factories from coal or diesel to natural gas and the development of strategies planning for energy efficiency and renewable energy. Currently, the government is developing two legislation projects to improve energy efficiency: Cogeneration Law and the design of the Colombian program of normalisation, accreditation, certification, and labelling of final use of energy equipment.

Hence, Colombian energy policies are based almost entirely on direct regulation. Apart from some small exemptions to VAT taxes for environmental investments, the principal use of economic incentives in energy policies involves the pricing of fuels and agreements with specific manufacturing industrial sector that have high potentials to improve energy efficiency or to carry out changes in technology and renewable energy.

\section{Methodology}

Changes in energy efficiency were monitored by examining energy use by unit of activity and the application of two indicators of energy efficiency. The first indicator $\left(\mathrm{EI}_{\mathrm{i}}\right) \mathrm{Measures}$ energy use per euro of gross production (equation 1); and the second indicator $\left(\mathrm{CEI}_{\mathrm{i}}\right)$ Carbon emission intensity the generation of greenhouses gases (in terms of $\mathrm{CO}_{2}$ emissions) per euro of gross production by each sector $i$ of German and Colombian manufacturing industry (equation 2).

$$
\begin{gathered}
E I_{i}=\frac{E_{i}}{P_{i}} \\
E I_{i}=\text { Energy intensity indicator }(\mathrm{Mj} / €) \\
E_{i}=\text { Energy consumption of the textile manufacturing activity } i(\text { e.g., Mj }) \\
P_{i}=\text { Production of textile sector } i(€) \\
C E I_{i}=\frac{C E_{i}}{P_{i}} \\
C E I_{i}=\mathrm{CO}_{2} \text { emissions intensity }\left(\mathrm{CO}_{2} \text { emissions } / €\right) \\
C E_{i}=\mathrm{CO}_{2} \text { emissions }(\text { tonnes })
\end{gathered}
$$

To identify the factors and variables that influencing energy efficiency in the German and Colombian manufacturing industries, we summarises the opinions and expectations of the main stakeholders (associations and representative firms in Germany and Colombia) through a questionnaire and existing scientific studies.

The questions were designed to identify factors and variables that determine energy efficiency in the manufacturing industries. It included three sections, each with a unique 
objective. The first section was designed to establish general information about energy consumption, structure of energy source and energy efficiency.

The second section was designed to assess and rank the importance of different factors and variables in the achievement of improved energy efficiency performance. Questions were asked on issues relating to economic, technical and political factors with their respective variables.

The third section was designed to assess external factors and instruments that would cause or encourage improvements in energy efficiency performance, and what kinds of internal measures or actions would tend to increase energy efficiency performance in the industry.

\section{Changes in energy efficiency in German and Colombian manufacturing industries}

Energy consumption in the manufacturing industries increased by $2.3 \%$ in Germany and $5.5 \%$ in Colombia during the sample period (figure 1). The manufacturing industries with the largest increases in energy consumption in this period were paper and tobacco in Germany, and the automotive industry and cement industry in Colombia, whereas the largest decrease in Germany was by the cement industry and in Colombia the machinery industry.

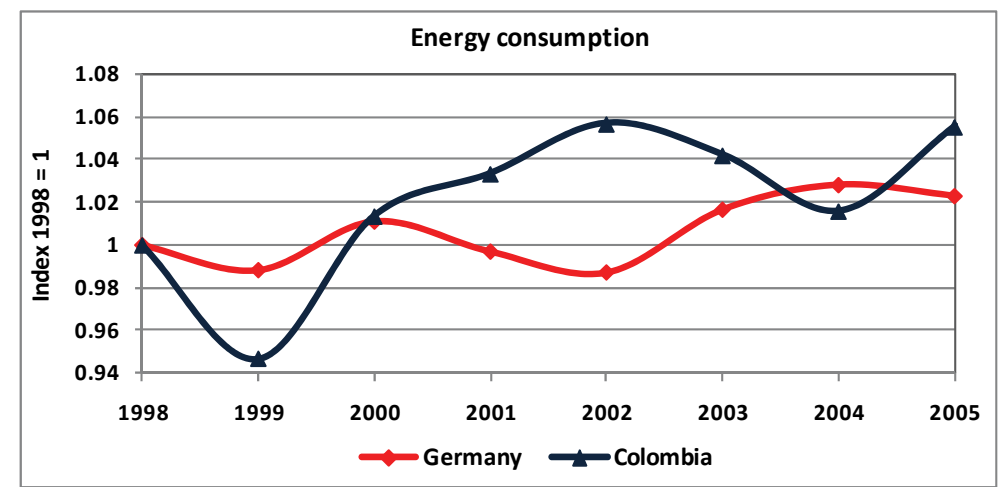

Fig. 1. Energy consumption developments in German and Colombian manufacturing industries

Figure 2 shows developments in average energy intensity for the German and Colombian manufacturing industries between 1998 and 2005. In Germany, this indicator decreased 11\% and in the Colombian case decreased $10 \%$. In both countries, several energy intensive sectors have driven the decreases in these indicators for the whole manufacturing sector (in the case of Germany, the chemical industry and basic metal, and in Colombia, basic metal and some sectors of the glass industry). 


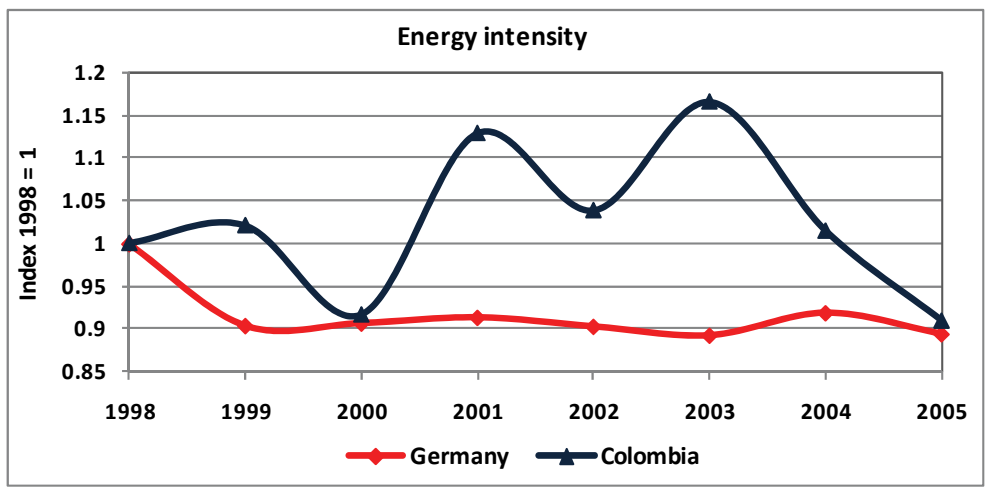

Fig. 2. Energy intensity developments for the German and Colombian manufacturing industries, 1998-2005

The indicator (CEIi) assessed in terms of generation of greenhouse gas emissions, specifically tonnes of $\mathrm{CO}_{2}$ per gross production. In Germany, the manufacturing industries this indicator decreased $10 \%$. The Colombian manufacturing industries decreased $13 \%$ this indicator (see figure 3).

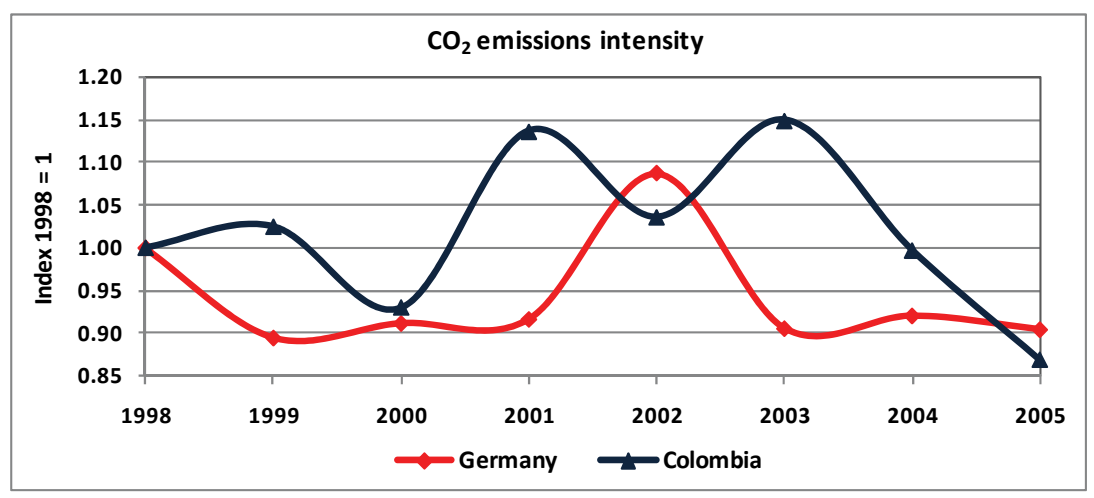

Fig. 3. $\mathrm{CO}_{2}$ emissions intensity developments for the German and Colombian manufacturing industries, 1998-2005

In Colombia, this indicator in general are still very high in comparison to the German manufacturing industries, and thus there are plenty of opportunities for the Colombian manufacturing industries to further lower this indicator and achieve better and cleaner production figures by improved use of energy resources and a better selection of fuels. By achieving these goals, Colombia will be able to meet international environmental requirements and thus will assure its permanence in the market. 


\section{Results and discussion}

The opinions and expectations of the main stakeholders as primary data are the following: In the German case, two associations and twelve companies, and in the Colombian case, four associations and 26 companies. (see figure 4).
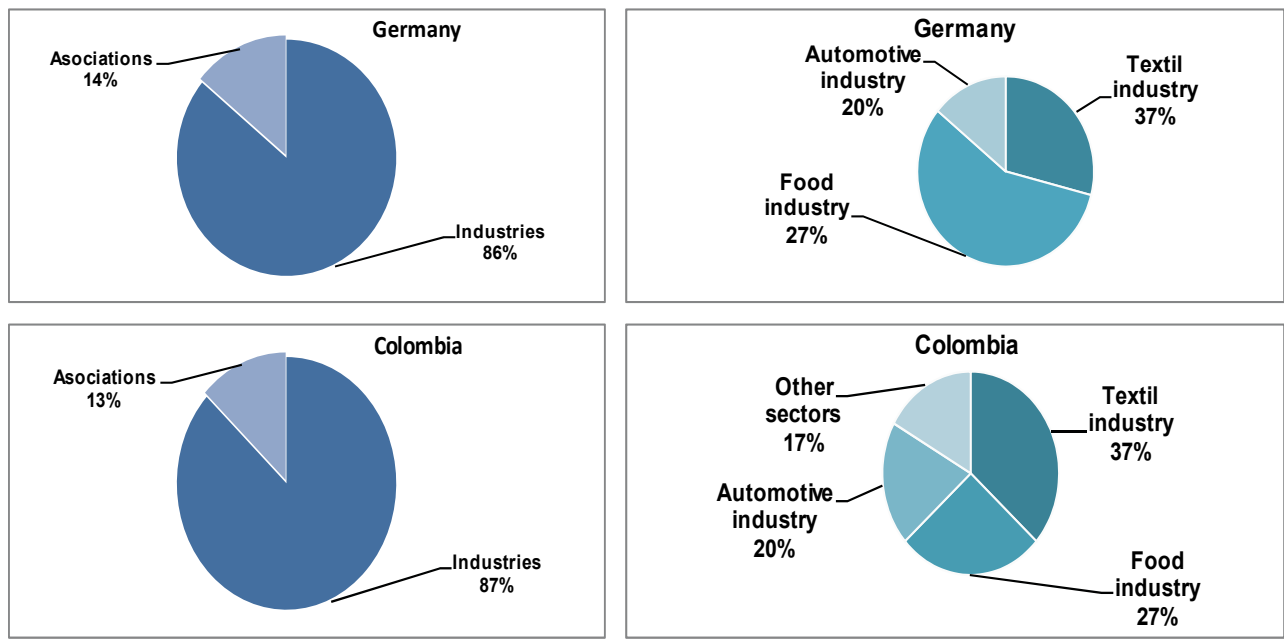

Fig. 4. Breakdown of the primary data from the German and Colombian associations and companies

\subsection{Features of energy consumption, energy efficiency and energy source in German and Colombian industries}

The results of primary data show that in the German and Colombian cases more than $50 \%$ of companies or associations consulted have made studies on energy efficiency and that within of these companies and associations, the majority has analysed and assessed energy efficiency performance and its advantages and disadvantages and included the topic of energy efficiency within their business plans and strategies.

The results also show that the majority of firms and associations know their energy consumption. However, in both countries, the assessment of energy intensity in the companies and associations is a fairly new topic. Moreover, from 2000 to 2008, the assessment of energy consumption and energy intensity has become more prevalent, indicating, possibly, that within the German and Colombian manufacturing industries, the energy topic is becoming more important in the production system and management. This trend would coincide with the increase in certifications of environmental management systems by the countries' in the German case $65 \%$ and in the Colombian case $30 \%$ by year during this period (ISO, 2007). Hence, energy management is a key program to improve sustainability and environmental performance.

In both countries, the main energy sources for the firms consulted are electricity and natural gas. Energy costs for the firms were between $0.5 \%$ and 3\% in the German case and between $0.5 \%$ and $5 \%$ in the Colombian case. 
The results in both countries indicate that energy management in the manufacturing industries is important for business strategy and that the quantification and assessment of energy consumption and energy efficiency are input indicators to improve upon in optimisation processes working towards sustainability.

\subsection{Factors influencing energy efficiency}

In the German case, $43 \%$ of firms and associations consider production technology factors very important, and $71 \%$ feel that economic and political factors are important in the improvement of energy efficiency performance. In the Colombian case, economic (69\%) and production technology factors (62\%) are very important factors in achieving improvement of energy efficiency, whereas the political factor is irrelevant (42\%) for firms and associations (see figure 5).

These results indicate that in the German case, the firms and associations consider that economic, technical as well as political factors influence energy efficiency, whereas in the Colombian manufacturing industries improvements in energy efficiency are only closely related with economic and production technology factors, mainly because energy efficiency policies are limited and are focalised mainly in support and recommendations of the better technologies.

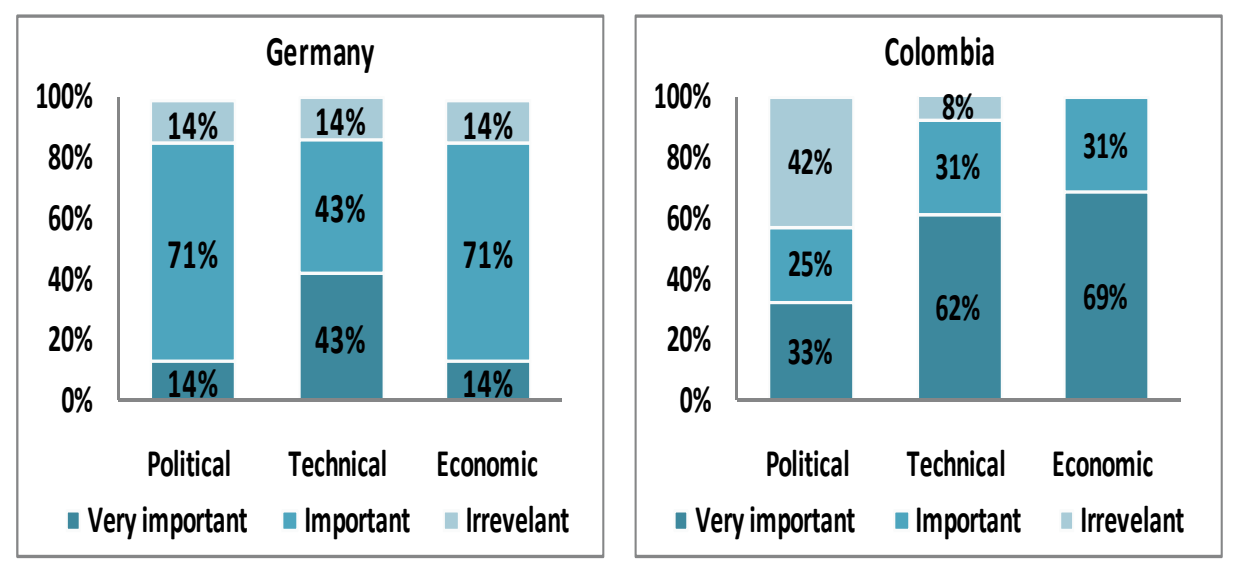

Fig. 5. Factors influencing energy efficiency in German and Colombian industries

- Variables in economic factors influencing energy efficiency

Energy consumption in the manufacturing industrial sector is influenced by the behaviour of several economic variables-e.g., high energy prices or constrained energy supply motivate industrial facilities to try to secure the amount of energy required for operations at the lowest possible price (McKane et al., 2008); structural changes in the manufacturing industries cause shifts in final energy use and energy intensities; and the plant capacity utilisation provides an indication of how efficiently plants and equipment are utilised and consequently, could measure the efficiency of energy use.

In the German case, the variables of the economic factor that have the most influence on energy efficiency are improvement in structural operations and maintenance costs and investments in new technologies, equipment or specific activities of energy management 
investments. Improvements in plant capacity utilisation and levels of production have less importance. On the other hand, in the Colombian case, all variables of the economic factor are important, but the most relevant are improvement in plant capacity utilisation and improvement in levels of production (see figure 6).

These results indicate that manufacturing industries of Germany consider that energy efficiency improvements have higher dependence of investments and production methods, whereas manufacturing industries of Colombia relate energy efficiency improvements with capacity and levels of production. This means that in Germany, improving energy efficiency is important as an investment strategy, whereas in Colombia, energy efficiency is a secondary result from production strategy. This finding concurs with Tholander et al., (2007) who identified the non-priority of energy efficiency investments and lack of access to capital-especially in small and medium enterprises - as main barriers to increased energy efficiency in the manufacturing industries of developing countries in contrast with the situation in developed countries. Moreover, manufacturing industries in developing countries likely prefers traditional investments like expansion of industrial plants or power generation. Furthermore, energy efficiency projects without large capital investments are often perceived as riskier and / or are too small to attract multilateral financial institution lending (UNIDO, 2007).
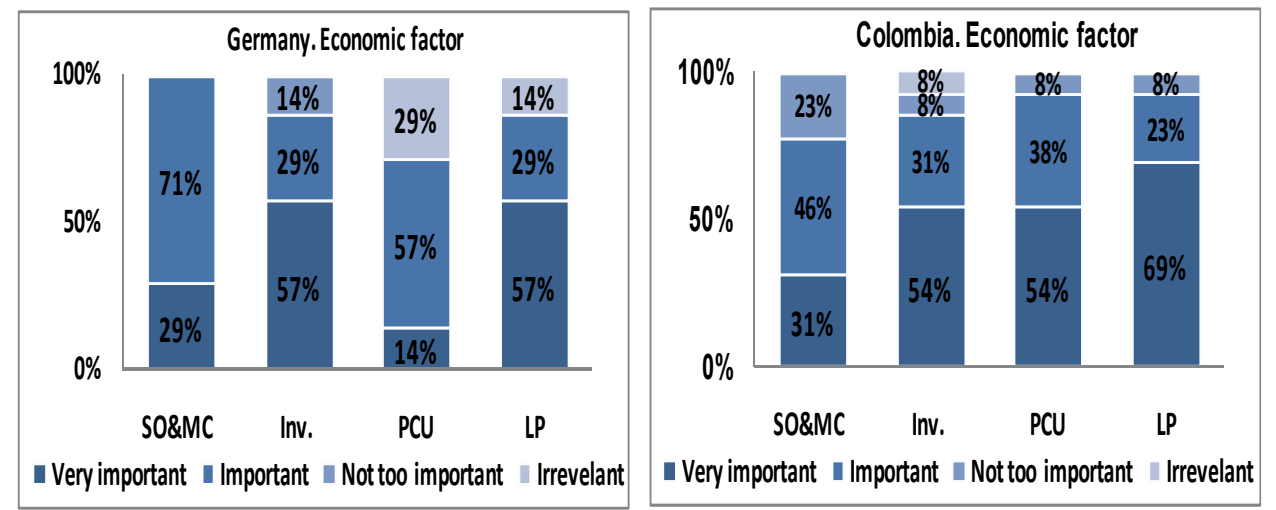

Fig. 6. Variables in the economic factors influencing energy efficiency in German and Colombian industries.

SOEMC: Improvement in the structure of operation and maintenance costs. Inv.: Investments in new technologies, equipments or specific activities of energy management. PCU: Improvement in plant capacity utilisation. LP: Improvement in levels of production.

\section{- Variables in production technology factor influencing energy efficiency}

The need for improvement of energy efficiency is just one of the drivers for technology development in industry. Moreover, the potential technical energy savings are available based on proven technologies, best practices and use of new energy sources (IEA, 2007). The manufacturing industries of both countries consider the most important technical variable in improving energy efficiency to be changes in process, operations and machinery. However, for German industries, changes in the structure of energy sources and 
consumption patterns are also important, while in the Colombian case, in the emphasis is on improved employment behaviour (see figure 7). These results concur with empirical analysis where energy sources emerging as an important variable that influences energy efficiency and in the case of automotive industry and food industry changes of raw materials have been a key variable to improve energy efficiency.
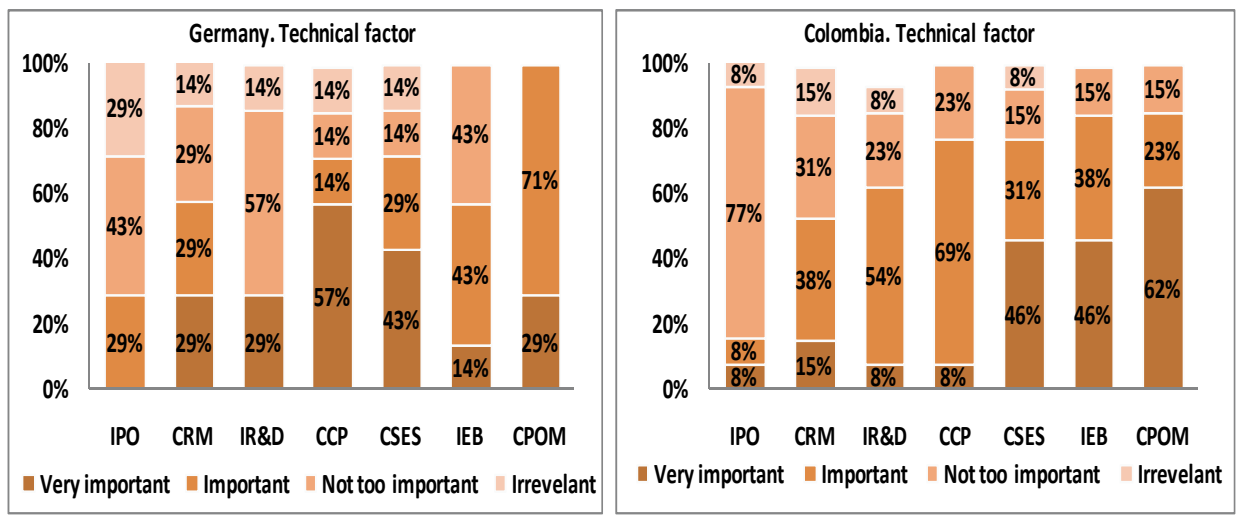

Fig. 7. Variables in the production technology factor influencing energy efficiency in German and Colombian industries.

IPO: Increase processes outsourcing. CRM: Changes of raw materials. IRED: Increase in the resources of RED. CCP: Changes of consumption patterns. CSES: Changes in the structure of energy sources. IEB: Improvements in employment behaviour. CPOM: Changes in the process, operations and machinery.

These results show that the manufacturing industries of both countries feel that the best way to improve energy efficiency is by changes in process, operations and machinery (Germany $71 \%$ and Colombia $62 \%$ ) generally these processes in the organizations begin with an internal analysis of the production process and machinery to determine opportunities to decrease energy consumption and increase energy efficiency. Moreover, in the Colombian case, it's also important the analysis of employment behaviour because behaviour change erodes the energy savings due to the technical energy efficiency improvements, especially in developing countries (IEA, 2005).

Hence, the results confirm that Germany has achieved important developments in energy efficient-technology and significant improvement in energy efficiency performance in the manufacturing industries. According to the Federal Ministry of Economics and Technology, Germany in recent years has achieved a decrease in its energy consumption even though the gross domestic product has more than doubled and German researchers and companies have submitted many global patent applications in the development of energy efficient industrial cross application technologies.

\section{- Variables in political factors influencing energy efficiency}

Market forces and other factors determine energy efficiency in the manufacturing industries. However, these factors can be influenced by an effective energy policy that encourages cost 
effective energy efficiency through the application of different types of policy instruments that include information, regulation and economic instruments.

Figure 8 shows the results of variables in the political factors affecting energy efficiency in German and Colombian industries. In the German case, the most important variables of the political factor are to encourage the application of energy management in the organizations, mandatory standards (such as the efficiency of electric motors and the efficiency of industrial boilers), and soft loans-especially for cogeneration (CHP). These results concur with Eichhammer, et al. (2006), who showed that only some measures are seen as a highimpact (the first voluntary agreement with German industry from 1995 and the second financial measures (CHP Act, KfW Umweltprogramm)), whereas the impact of the Ecological Tax Reform has been estimated as medium, and other measures have been assessed as low-impact.

However, according to studies of Ecofis et al., (2206) voluntary agreements to save energy are adequate in these circumstances when dealing with a small number of actors with which you need to negotiate or a strongly organized sector and / or when there is much relatively cheap energy saving potential. The characteristics that could determine the success of this instrument are the following: the target group motivated to participate, there are penalties in case of non- compliance, there is a good monitoring system, and adequate supporting instruments such as audits, energy monitoring systems, financial incentives and demonstrations projects.
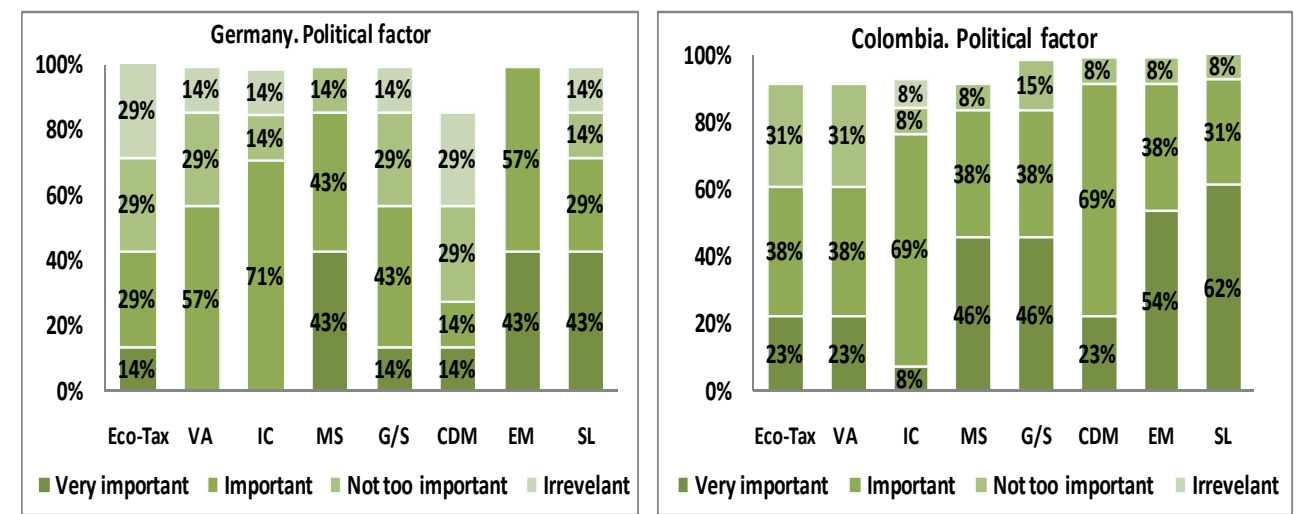

Fig. 8. Variable in the political factors influencing energy efficiency in German and Colombian industries

Eco-tax: Eco-tax.VA: Voluntary audits. IC: Information campaigns. MS: Mandatory standards (the efficiency of electric motors and the efficiency of industrial boilers). G/S: Grants / subsidies. CDM: Emission trading / Clean Development Mechanism. EM: to encourage the application of energy management SL: Soft Loans for Energy Efficiency, Renewable energy and CHP.

In the Colombian firms, the most important variables are soft loans (for Energy Efficiency, Renewable energy and cogeneration ( $\mathrm{CHP})$ ), to encourage energy management and the emissions trading / Clean Development Mechanism-indicating that in this country, a barrier to improved energy efficiency is the limited amount of resources available to change 
technology and to achieve improved energy efficiency, a conclusion which concurs with the studies of Kant, 1995; Tanaka, 2008 and Gillingham et al., 2009.

\subsection{Instruments influence interest to improve energy efficiency performance}

Figure 9 shows that instruments and measures would cause or encourage the German and Colombian manufacturing industries to improve energy efficiency performance. In both countries, the main instruments are changes in upstream sector (energy prices) and institutional regulations, whereas labelling to have a lower impact.
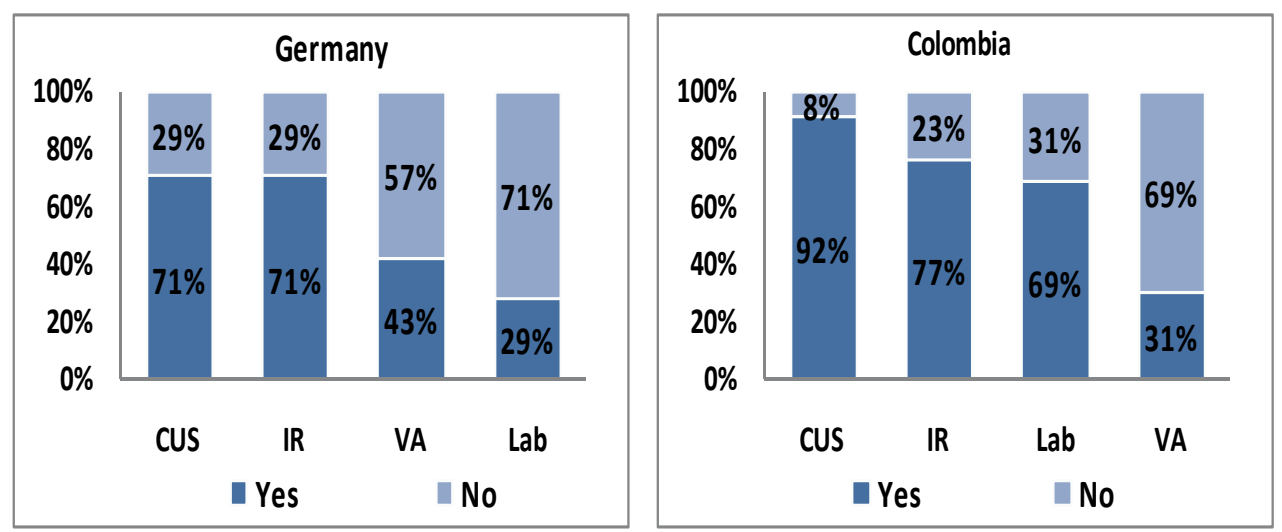

Fig. 9. Percentage of respondents who felt that specific measures and instruments could improve energy efficiency performance

CUS: Changes in upstream sector (energy prices). IR: Institutional regulations (Regulatory standards, - Fiscal policy, State aid for RED). VA: Voluntary agreements. Lab: Labelling (e.g. industrial motors, EMAS, ISO 14001).

The results are clear in the German case, where a series of energy-conservation instruments have been implemented to include: the replacement of traditional gas- or oil-fired boilers with condensing gas-fired boilers, the gradual replacement of traditional fuels with more expensive bio-fuel, and the consecutive emergence of integrated gasification combined cycle (CGC) and combined heat and power (CHP) systems. As a result, the energy intensity of Germany has decreased 20\% from 1990 to 2003, with an annual decrease rate of $1.75 \%$. Moreover, during the last decade, the energy policy of Germany has been strongly influenced by environmental issues, and the German government has consecutively introduced various acts related to renewable energy and energy efficiency. During 1999, to stimulate energy conservation, energy efficiency, and the application of renewable energy technologies, the German government introduced the Eco-tax, which subsequently became the Renewable Energy Act, which targets a short-term goal of doubling renewable power generation by 2010, together with an intermediate-term goal of increasing renewable power generation capacity to $20 \%$ of total power generation capacity by 2020 (Blesl et al., 2007). 


\subsection{Internal measures and actions the manufacturing industries would consider to increase energy efficiency performance}

Figure 10 shows the kinds of internal measures and actions the manufacturing industries would consider to increase energy efficiency performance. In the German case, the most important internal measures in order of importance are energy management systems, energy efficiency investments, and changes in machinery and equipment. In the Colombian case, the most important internal measures in order of importance are energy efficiency investments, changes in machinery and equipment, and optimisation of production capacity and production level.
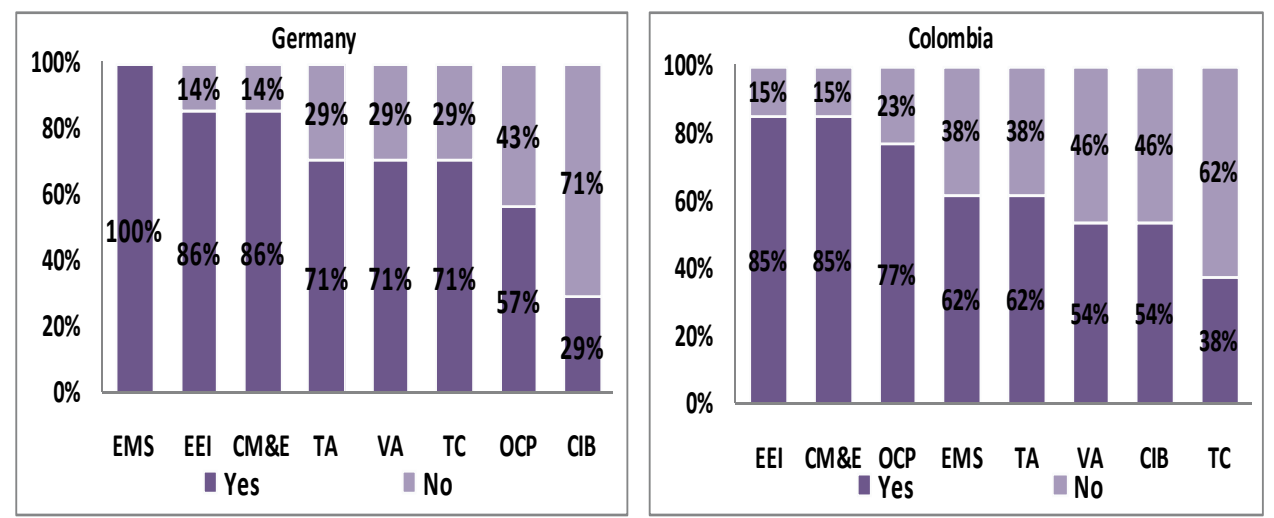

Fig. 10. Kinds of internal measures and actions the manufacturing industries would consider to increase energy efficiency performance

EMS: Energy management systems. EEI: Energy efficiency investment (e.g. changes in machinery, equipments and technology). CMEE: Changes in machinery and equipment. TA: Training activities. VA: Voluntary audit. TC: Major product/process related technological changes, whether or not introduced as part of public/private national and the RED programmes. OCP: Optimization of production capacity and production level. CIB: Conversion of industrial business (in terms of both products and processes).

These results show that in both countries, the manufacturing industrial sector has an interest in increasing their investments to improve energy efficiency through changes in machinery and equipment-demonstrating that the manufacturing industrial sector considers improvements in energy efficiency to be closely related with technological change. This result coincides with opportunities to improve industrial energy efficiency through new technologies such as the use of high-efficiency motor-driven systems, the optimisation of compressed air systems and the potential that exists based on currently available improvements. In fact, the possibility of implementing new and emerging technologies with potential savings of as much as 35 percent in energy costs is creating entirely new lines of business (IAC, 2007).

Finally, the results of this study suggest that policy strategies in the manufacturing industries have to utilise legal and fiscal instruments to generate supporting framework conditions as well as targeted programs in the fields of $R \& D$, technological change, market transformation, information, education, dissemination of best practice, etc. Moreover, policy 
will always have to live with unavoidably sub-optimal solutions, while growing knowledge and changing frameworks will constantly impose the need to search for better solutions and new opportunities. In this context, energy policy strategies represent not only (static) problems of policy choice but-above all-dynamic search and learning processes aimed at designing effective policy measures.

\section{Recommendations for the formulation of energy-efficiency policies in the Colombian manufacturing industrial sector}

According to our results and the literature, it is important that there be a formulation of an adequate package of policies and measures that are addressed to guarantee effective and efficient impact to improve energy-efficiency performance and reducing greenhouse emissions in the Colombian manufacturing industries. The following strategies and instruments in policy settings are recommended in order to achieve improvements in energy efficiency in a cost-effective manner:

a. Policy support. Policy support should aim at making energy efficiency easy ("Make it easy!"), realisable ("Make it possible!"), and beneficial ("Make it rewarding!") for stakeholders, thereby contributing to the development of the market for energy-efficient technologies and services. Due to the implementation of the support programmes, it also becomes clear that energy efficiency is politically intended and crucial ("Make it a policy!"). A pre-planned, target-group-specific, differentiated mix of policy instruments and measures is necessary, with integrated measures that are directly addressed to stakeholders. In such a way, the specific situations, incentives, barriers and obstacles of different stakeholders should be addressed by specific policy mixes (Thomas and Irrek, 2007).

b. Integral approach. The most effective way to improve industrial energy efficiency is through an integrated approach, where a number of policies and programmes are combined to create a strong overall industrial energy-efficiency policy that addresses a variety of needs in Colombian manufacturing sectors. There should thus be an adoption of a policy of energy-efficiency sector targets and related programmes in which individual manufacturing industrial sectors committed to specific improvements in energy intensity over a given time period in exchange for governmental support in the form of financial incentives, information programmes, demonstration programmes, and training programmes, significant energy savings could be realised.

c. Energy efficiency strategies. National energy efficiency strategies in Colombia could accelerate the implementation of energy efficiency in the manufacturing industries. National energy-efficiency strategies should be useful because during their development, implementation and evaluation, they can help to achieve the following: make the vision for energy efficiency explicit; focus attention on the important issues; identify gaps in current work programmes; identify necessary tasks and resources and allocate implementation and monitoring responsibility.

d. Energy data. The Colombian government through the statistical office and energy agency (UPME) must improve the availability of high-quality energy efficiency data because 
without accurate energy time series data, it is difficult to target and develop appropriate energy efficiency policies in the manufacturing industries. Moreover, for developing sectoral energy efficiency benchmarks and best practices, action plans should: assess energy consumption by end-use in manufacturing industrial sector; identify the economy's energysaving potentials and establish objectives and adequate methods for evaluating the success of the plan.

e. Mandatory standards. For the Colombian manufacturing industrial sector, the most important technical variable to improve energy efficiency is change in processes, operations, machinery and equipment. For this reason, the Colombian government should consider adopting mandatory minimum energy performance standards for machinery and equipment (e.g., the efficiency of industrial motors and the efficiency of industrial boilers) in line with international best practices. Moreover, it should examine barriers to the optimisation of energy efficiency through technology systems and design and implement comprehensive policy portfolios aimed at overcoming such barriers.

f. Energy management. Among Colombian firms, one of the most important political variables is the encouragement of the application of energy management ${ }^{5}$. The Colombian government should thus consider providing effective assistance in the development of energy management (EM) capability through the development and maintenance of EM tools, training, certification and quality assurance. Moreover, it should encourage or require major industrial energy users to implement comprehensive energy management procedures and practices that could include, according to IEA, 2008:

- $\quad$ The development and adoption of a formal energy management policy. The process and implementation of this policy should be reported and overseen at the company board level and reported in company reports. Within this policy, companies would need to demonstrate that effective organisational structures have been put in place to ensure the following: that decisions regarding the procurement of energy-using equipment are taken with the full knowledge of the equipment's expected life-cycle costs and that procurement managers have an effective incentive to minimise the lifecycle costs of their acquisitions.

- $\quad$ The appointment of full-time qualified energy managers at both the enterprise- and plant-specific levels as appropriate.

- The establishment of a scheme to measure, monitor, evaluate and report industrial energy consumption and efficiency at the individual company sector and national levels. As a part of this effort, appropriate energy performance benchmarks should be developed, monitored and reported at levels deemed suitable for each sector.

g. Small and Medium-sized Enterprises (SMEs). The size of company variable was significant for Colombian industry. The Colombian government should thus consider

\footnotetext{
${ }_{5}$ There are significant cost-effective energy savings to be realised in industry through the more widespread adoption of best practices in energy management (EM). EM addresses the way in which an industrial plant or facility is managed to identify and exploit cost-effective energy savings opportunities (IEA, 2008).
} 
developing and implementing a package of policies and measures to promote energy efficiency among SMEs. This package should include: a system for ensuring that energy audits, carried out by qualified engineers, are widely promoted and easily accessible for all SMEs; the provision of high-quality and relevant information on energy-efficiency best practices; the provision of energy performance benchmarking information that ideally would be structured to allow international and national economy comparisons; and appropriate incentives to adopt capital acquisition and procurement procedures with the lowest life-cycle costs.

h. Investments. For the Colombian manufacturing industrial sector, the results indicate that energy efficiency investments are a key variable to improve energy efficiency. However, among the many impediments to the adoption of cost-effective energy efficiency investments is the "finance barrier" (Tholander et al., 2007 and IEA, 2008). The Colombian government should facilitate the manufacturing industrial sector's and stakeholders' involvement in energy efficiency investments by: I) adopting and publicising to the manufacturing industrial sector a common energy-efficiency savings verification and measurement protocol in order to reduce existing uncertainties in quantifying the benefits of energy efficiency investments and stimulate increased private sector involvement; II) reviewing their current subsidies and fiscal incentive programmes to create more favourable grounds for private energy-efficiency investments; III) collaborating with the private financial sector to establish public-private tools to facilitate energy-efficiency financing; IV) promoting risk-mitigation instruments such as securitisation or public-private partnerships; V) putting in place institutional frameworks to ensure regular co-operation and exchanges on energy efficiency issues between the public sector and financial institutions and VI) design an energy tax programme to provide an incentive to industry to improve energy management at firms' facilities through both behavioural changes and investments in energy-efficient equipment.

i. Taxes and tariff structure. This study demonstrated that energy costs and taxes are important for improving energy efficiency. The Colombian government should design a package of taxes and a tariff structure that include the following: I) the reduction of subsidies or using energy to balance the effect of subsidies, providing the energy consumer with a more realistic indication of the actual costs associated with certain forms of energy; II) the use of taxes to more accurately reflect the environmental costs, or "externalities", associated with energy consumption; III) the imposition of taxes and fees associated with energy use resulting from energy consumption on users with the goal of creating incentives to reduce wasteful energy consumption practices or creating public programmes and funds for encouraging energy efficiency and IV) having the price system ensure that all individual agents are confronted with the full costs that their decisions impose on others; this means addressing externalities and market failures through a greater use of taxes, charges and tradable permits and correcting policy failures through reforms of support programmes that are environmentally harmful and economically inefficient and have undesirable social effects.

j. Control, monitoring and evaluation. Developing effective energy-efficiency policies requires a good understanding of how energy is used as well as the various factors that 
drive or restrain demand. Such an understanding requires accurate data on energy end-use and the associated activities. The Colombian government should thus ensure that instruments of energy efficiency policies are adequately monitored, enforced and evaluated so as to ensure maximum compliance and that their energy-efficiency policies are supported by adequate end-use information by substantially increasing their effort to collect energy end-use data across all sectors and relating to all energy types.

k. Technology transfer and cooperation. In the Colombian manufacturing industrial sector, this analysis demonstrated that the technology level is still moderate and that this technical factor is a key strategy to improve energy efficiency. The Colombian government should thus promote technology transfer through an appropriate enabling framework in order to enhance international cooperation for the scaling up of sustainable energy solutions. The transfer of technology requires a careful balancing act that includes both fair treatment for innovators and energy policies that stimulate global diffusion of energy technology to address energy efficiency.

\section{Conclusions}

In this chapter analysed the energy efficiency in German and Colombian manufacturing industries in the time period 1998-2005 using economic indicators. We found that the industrial sectors of both countries during the sample period increased their energy consumption by $2.3 \%$ in Germany and $5.5 \%$ in Colombia and also decreased the energy intensity (11\% and 10\% respectively). Therefore, German and Colombian manufacturing industries improved energy efficiency and decreased $\mathrm{CO}_{2}$ emissions demonstrating that the trend of manufacturing industry is "make more with less energy consumption and clean production".

Based on the primary data from German and Colombian industrial associations and representative firms in each country, the economic, technical and political factors were studied with respect to impact on energy efficiency. The results in both countries indicate that energy management for the manufacturing industrial sector is important within business strategy and that the quantification and assessment of energy consumption and energy efficiency are input indicators to be used in improvement and optimisation processes within sustainability development.

The results also show that in German industry, economic, technical and political factors influence energy efficiency, whereas in the Colombian case, improvements in energy efficiency are closely related with economical and production technology factors.

In the German case, the results showed the following: (I) the variables in the economic factor with the most influence on energy efficiency are the structural operations and maintenance costs and investments, whereas plant capacity utilisation and levels of production have lower importance. (II) The most important technical variables to improve energy efficiency are changes in the processes, operations and machinery, changes in the structure of energy sources, and changes of consumption patterns. (III) The most important variables in the political factor are to encourage the application of energy management, mandatory standards (such as the efficiency of electric motors and the efficiency of industrial boilers), and soft loans especially for cogeneration (CHP). (IV) The most important internal measures 
to improve energy efficiency are energy management systems, energy efficiency investment, and changes in machinery and equipment.

In the Colombian case, the results showed the following: (I) All variables for the economic factor are important, but the most relevant are plant capacity utilisation and levels of production. (II) The most important technical variables to improve energy efficiency are changes in the processes, operations and machinery, and improvements in employment behaviour. (III) The most important variables of the political factor are soft loans (for Energy Efficiency, Renewable energy and cogeneration (CHP)), to encourage the application of energy management and emissions trading / Clean Development Mechanism. (IV) The most important internal measures for increasing energy efficiency are energy efficiency investments, changes in machinery and equipment and optimisation of production capacity and production level.

Moreover, the results suggest that policy strategies in the Colombian manufacturing industrial sector have to combine the following strategies: integral approach, energy data, mandatory standards, energy management, the promotion of energy efficiency in small and medium-sized enterprises, investments, a tax program, an adequate tariff structure, control and evaluation, technology transfer and cooperation.

\section{Acknowledgments}

The author would like to thank Professor Dr Werner Bönte, Dr Wolfang Irrek and Dr Alexander Cotte Poveda for the helpful suggestions and comments. The author is grateful for the support provided by the Wuppertal Institute, Deutscher Akademischer Austausch Dients and the University of La Salle. Any remaining errors are the responsibility of the author.

\section{References}

Blesl M., Das A., Fahl U., Remme U. (2007). Role of energy efficiency standards in reducing CO2 emissions in Germany: An assessment with TIMES. Energy Policy 35, 772-785.

Blackman A, Morgenstern R., Montealegre L., Murcia L., and García J. (2006). Review of the efficiency and effectiveness of Colombia's environmental policies. An RFF Report.

Kant A. (1995). Strategies and Instruments to promote energy efficiency in developing countries. Project working paper 5. Effectiveness of industrial energy conservation programmes in IEA countries ECN-C-94-113.

ECOFYS, Wuppertal Institut, Lund University. (2006). Guidelines for the monitoring, evaluation and design of energy efficiency policies. How policy theory can guide monitoring and evaluation efforts and support the design of SMART policies. www.aid-ee.org

Eichhammer, W., Schlomann, B., Kling N. (2006). Energy Efficiency Policies and Measures in Germany 2006. Monitoring of Energy Efficiency in EU 15 and Norway (ODYSSEEMURE). Fraunhofer Institute for Systems and Innovation Research (Fraunhofer ISI).

Gillingham K., Newell R., Palmer K. (2009). Energy efficiency economics and policy. Working Paper 15031. http:/ / www.nber.org/papers/w15031

International Energy Agency (IEA). (2008). Energy efficiency policy recommendations. In support of the G8 Plan of Action. http://www.iea.org/G8/2008/G8_EE_ recommendations.pdf 
International Standard Organisation (ISO). (2007). The ISO Survey of Certifications 2006. www.iso.org

Inter Academy Council (IAC). (2007). Lighting the way. Toward a sustainable energy future. www.interacademycouncil.net

International Energy Agency (IEA). (2005). The experience with energy efficiency policies and programmes in IEA countries. Learning from the critics. IEA Information paper.

International Energy Agency (IEA). (2007). Tracking Industrial Energy Efficiency and CO2 Emissions. In support of the G8 Plan of Action. Energy Indicators.

Larsen E., Dyner. I, Bedoya L., Franco C. (2004). Lessons from deregulation in Colombia: successes, failures and the way ahead. Energy policy 32, 1767-1780.

McKane A., Price L., Rue S. (2008). Policies for Promoting Industrial Energy Efficiency in Developing Countries and Transition Economies. United Nations Industrial Development Organization.

Tanaka K. (2008). Assessment of energy efficiency performance measures in industry and their application for policy. Energy policy (2008), doi:10.1016/j.enpol.2008.03.032.

Thomas S., Irrek W. (2007). Wie 20 Prozent Endenergieeinsparung möglich werden können. Worschläge des Wuppertal Instituts zum deutschen Energieeffizinez-Aktionsplan und zu Maßnahmen im Industriebereich. VIK Mitteilungen 3/07, 16-18.

Thollander P., Danestig M., Rohdin P. (2007). Energy policies for increased industrial energy efficiency: Evaluation of a local energy programme for manufacturing SMEs. Energy policy $35,5774-5783$.

United Nations Industrial Development Organization (UNIDO). (2007). Policies for promoting industrial energy efficiency in developing countries and transition economies. Commission for Sustainable Development (CSD-15).

Wuppertal Institute, 2008. Greenhouse Gas Mitigation in Industry in Developing Countries. Final Report. On behalf of the Deutsche Gesellschaft für Technishe Zusammenarbeit (GTZ). http://www.wupperinst.org/en/projects/proj/index. 


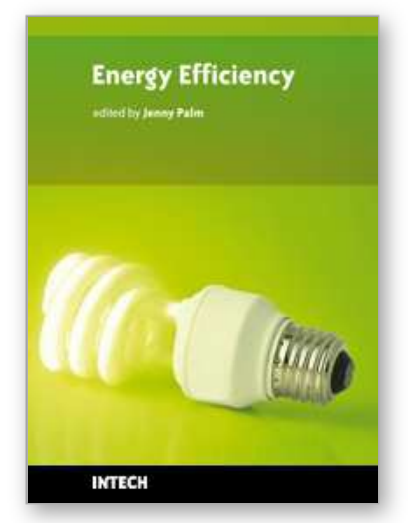

\author{
Energy Efficiency \\ Edited by Jenny Palm
}

ISBN 978-953-307-137-4

Hard cover, 180 pages

Publisher Sciyo

Published online 17, August, 2010

Published in print edition August, 2010

Global warming resulting from the use of fossil fuels is threatening the environment and energy efficiency is one of the most important ways to reduce this threat. Industry, transport and buildings are all high energyusing sectors in the world and even in the most technologically optimistic perspectives energy use is projected to increase in the next 50 years. How and when energy is used determines society's ability to create long-term sustainable energy systems. This is why this book, focusing on energy efficiency in these sectors and from different perspectives, is sharp and also important for keeping a well-founded discussion on the subject.

\title{
How to reference
}

In order to correctly reference this scholarly work, feel free to copy and paste the following:

Clara Pardo Martinez (2010). Factors Influencing Energy Efficiency in the German and Colombian Manufacturing Industries, Energy Efficiency, Jenny Palm (Ed.), ISBN: 978-953-307-137-4, InTech, Available from: http://www.intechopen.com/books/energy-efficiency/factors-influencing-energy-efficiency-in-the-germanand-colombian-manufacturing-industries

\section{INTECH}

open science / open minds

\section{InTech Europe}

University Campus STeP Ri

Slavka Krautzeka 83/A

51000 Rijeka, Croatia

Phone: +385 (51) 770447

Fax: +385 (51) 686166

www.intechopen.com

\section{InTech China}

Unit 405, Office Block, Hotel Equatorial Shanghai

No.65, Yan An Road (West), Shanghai, 200040, China

中国上海市延安西路65号上海国际贵都大饭店办公楼 405 单元

Phone: +86-21-62489820

Fax: +86-21-62489821 
(C) 2010 The Author(s). Licensee IntechOpen. This chapter is distributed under the terms of the Creative Commons Attribution-NonCommercialShareAlike-3.0 License, which permits use, distribution and reproduction for non-commercial purposes, provided the original is properly cited and derivative works building on this content are distributed under the same license. 